\title{
KAJIAN JEMBATAN KECAMATAN SENDANG (RUAS JALAN TUGU - PABYONGAN) KABUPATEN TULUNGAGUNG DENGAN METODE KOMPOSIT
}

\author{
Tri Yuli Purnomo ${ }^{1}$, Lucia Desti Krisnawati², Yosef Cahyo SP³. \\ ${ }^{1,2,3}$ Fakultas Teknik, Universitas Kadiri. \\ e-mail:.1 triyulipurnomo@gmail.com,2lucia desti@unik-kediri.ac.id, \\ 3yosef.cs@unik-kediri.ac.id.
}

\begin{abstract}
Population growth in Tulungagung Regency, which is getting faster, must be balanced with adequate transportation infrastructure. Improvement of transportation facilities and infrastructure is in the form of bridge construction. In order to achieve good and truly mature planning, a careful feasibility study is required. From the results of research on the Sendang Bridge (Tugu - Pabyongan Road Section), the greatest force acting on the bridge includes: ultimate moment of support $=34.7 \mathrm{kNm}$ and the ultimate moment of field $=23.8 \mathrm{kN}$, dead load $=101.12 \mathrm{kNm}$, live load $=11.09 \mathrm{kN} / \mathrm{m}$, load ' $D$ ' $=304.73 \mathrm{kNm}$, load ' $T$ ' $=130 \mathrm{kN}$, brake load $=45.93 \mathrm{kNm}$, wind load $=14.70 \mathrm{kNm}$, earthquake load $=1,1 \mathrm{kN} / \mathrm{m}$. From the existing loading, a bridge plate with a thickness of $0.2 \mathrm{~m}$ is determined. The controls used were deflection requirements $d<L s / 240.0 .0313<10.8 / 240 \rightarrow O K$, control voltage kip $f=16.77 \mathrm{Mpa}$. The girder profile is used WF 400.200.8.13. By calculating the structural load and the force acting on the bridge, the use of girder profile is safe to accept stress and deflection due to the forces on the upper structure.
\end{abstract}

Keywords : Bridge, Composite, Upper structure, Transportation

\begin{abstract}
Abstrak
Pertumbuhan penduduk di Kabupaten Tulungagung yang semakin pesat harus diimbangi dengan sarana prasarana transportasi yang memadai. Peningkatan sarana dan prasarana transportasi ini berupa pembangunan jembatan. Untuk mencapai perencanaan yang baik dan benar-benar matang maka diperlukan studi kelayakan yang teliti. Dari hasil penelitian pada Jembatan Sendang (Ruas Jalan Tugu - Pabyongan) dihasilkan Gaya yang terbesar yang bekerja pada jembatan meliputi : momen ultimite tumpuan sebesar = $34,7 \mathrm{kNm}$ dan momen lapangan ultimit sebesar $=23,8 \mathrm{kN}$, beban mati $=101,12 \mathrm{kNm}$, beban hidup $=11,09$ $\mathrm{kN} / \mathrm{m}$, beban ' $\mathrm{D}$ ' $=304,73 \mathrm{kNm}$, beban ' $\mathrm{T}$ ' $=130 \mathrm{kN}$, beban rem $=45,93 \mathrm{kNm}$, beban angin $=14,70 \mathrm{kNm}$, beban gempa $=1,1 \mathrm{kN} / \mathrm{m}$. Dari pembebanan yang ada ditentukan Plat jembatan setebal $0,2 \mathrm{~m}$. Kontrol kontrol yang di gunakan syarat lendutan $d<\mathrm{Ls} / 240$. 0,0313 $<10,8 / 240 \rightarrow \mathrm{OK}$, kontrol tegangan kip $\mathrm{f}=$ 16,77 Mpa. Profil gelagar digunakan WF 400.200.8.13, dengan perhitungan beban struktur dan gaya yang bekerja pada jembatan, penggunaan profil gelagar tersebut aman menerima tegangan dan lendutan akibat gaya-gaya pada struktur atas.
\end{abstract}

Kata Kunci : Jembatan, Komposit, Struktur atas, Transportasi 


\section{PENDAHULUAN}

Jembatan merupakan salah satu akses yang menghubungkan antara daerah yang satu dengan daerah lainnya yang terpisah karena keadaan alam, misalnya adanya lembah, jurang, sungai maupun rel kereta api. Pada kawasan perkotaan yang lalu lintasnya padat, jembatan juga bisa menjadi alternatif untuk menghindari kemacetan, [1][2].

Pada studi kajian ini, dengan adanya pembangunan Jembatan Kecamatan Sendang (Ruas Jalan Tugu - Pabyongan)dengan bentang 36 meter( $3 \times 12 \mathrm{~m}$ ) maka perlu adanya perhitungan kekuatan struktur guna mengetahui efektifitas dan factor ekonomis pembangunan jembatan tersebut, [3].

Berdasarkan uraian diatas dapat dirumuskan permasalahan sebagai berikut :

1. Bagaimana pembebanan berdasarkan statika yang ada?

2. Bagaimana pembebanan lantai kendaraan yang timbul?

3. Bagaimana desain yang digunakan untuk gelagar induk?

4. Bagaimana pembebanan plat injak?

Agar pembahasan tugas akhir ini mencapai sasaran dan tujuan dengan tepat, maka perlu diberi batasan masalah. Adapun batasan masalah dalam skripsi ini meliputi:

1. Perhitungan sandaran dan tiang sandaran

2. Perhitungan lantai kendaraan

3. Perhitungan gelagar induk

4. Perhitungan plat injak

Maksud penelitian ini antara lain :

1. Memahami perhitungan analisa struktur jembatan dengan sistem komposit antara baja dan beton.

2. Mengetahui kekuatan struktur pada Jembatan Sendang.

Tujuan dari penelitian ini adalah memberikan alternatif perencanaan dengan pertimbangan faktor- faktor yang terkait dengan dasar tujuan untuk mengusahakan agar kontruksi alternatifnya memberi beberapa keuntungan atau kelebihan jika dibandingkan dengan kontruksi yang sudah ada, .

\section{METODE PENELITIAN}

\subsection{Tahapan Penelitian}

Metode penelitian yaitu pengambilan data yang erat dikaitkan dalam penulisan tugas akhir ini seperti data gambar, data lalu lintas kendaraaan, kemudian dihitung struktur pembebanan dan gaya yang bekerja pada jembatan, kemudian ditarik kesimpulan kekuatan struktur pada Jembatan Sendang tersebut, [4][5]. 


\subsection{Jembatan}

Jembatan adalah suatu konstruksi yang gunanya untuk meneruskan jalan melalui rintangan yang permukaannya lebih rendah, [6][7]. Rintangan ini biasanya (jalan, air, atau jalan lalu lintas).Jembatan merupakan investasi tertinggi dari semua elemen yang dapat di jumpai pada sistem jalan raya. Setiap kerusakan pada konstruksi tidak hanya merupakan suatu reduksi dalam investasi, akan tetapi lebih penting lagi dapat merupakan penyebab timbulnya gangguangangguan dalam kelancaran perputaran roda ekonomi serta dapat menimbulkan kecelakaan bagi manusia, [8][9].

\subsection{Jembatan Komposit}

Penampang komposit terbentuk jika dua buah komponen bahan (Baja-Beton) digabung menjadi satu kesatuan penampang dan terjadi intreaksi antara komponenkomponen tersebut yang berupa Lantai beton dan Balok baja dalam menahan beban kerja, masing-masing karakteristik dasar dan meterialnya dari dua komponen tersebut dimanfaatkan secara optimal [10]. Agar terbentuknya interaksi yang baik antara dua komponen tersebut, gaya geser yang terjadi antara lantai beton dan balok baja ditahan oleh Penghubung Geser (Shear Connector), [11].

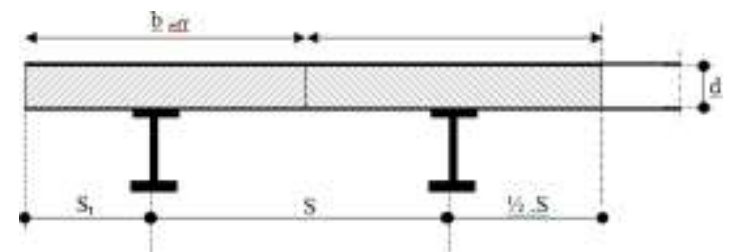

Gambar 1. Penampang Komposit

\subsection{Dimensi Balok Gabungan Komposit}

Umumnya gelagar baja terdiri dari profil IDIN dengan plat perkuatan sayap tepi bawah, tetapi gelagar baja biasa tidak mencukupi maka dibuat dari profil tersusun, diman plat sayap dan badan dihubungkan dengan las. Dimensi balok gabungan ini kita hubungan dengan sistem cobacoba. Dengan tebal plat lantai beton minimum $15 \mathrm{~cm}$ sehingga kita kontrol tegangan-tegangan yang terjadi berdasarkan :

Bila waktu pemasangan lantai beton tidak diadakan tumpuan pembantu (perancah/bekesting).Tegangan yang timbul akibat berat sendiri (lantai beton sebelum mengeras + gelagar) dipikul oleh gelagar baja, beban bergerak dengan tumbukan dipikul oleh gelagar composite.Tetapi akibat muatan-muatan lainnya seperti (sandaran, aspal, trotoar) karena pada umumnya dikerjakan setelah bagian-bagian utama selesai/mengeras atau lantai beton yang menimbulkan tegangan tambahan.Perhitungan tegangan tambahan ini memungkinkan beton dalam keadaan plastis, sehingga kita tidak menggunakan beton dalam keadaan modulus elastis, tetapi menggunakan beton dengan yang lebih besar yaitu $\mathrm{n}$ plastis. 
Bila gelagar tersebut diberi tumpuan pembantu (perancah/bekisting) pada saat pengecoran lantai beton sampai mengering mencapai $75 \%$ dari kekuatan seharusnya (kekuatan setelah 28 hari) baru tumpuan pembantu tersebut dibuka, sehingga baik akibat berat sendiri maupun beban bergerak maupun beb $\mathrm{n}$ bergerak diperhitungkan yang memikul adalah gelagar komposit, [12][13].

\subsection{Beton Bertulang}

Standar Perencanaan Struktur Beton untuk Jembatan ini digunakan untuk merencanakan jembatan jalan raya dan jembatan pejalan kaki di Indonesia, yang menggunakan komponen struktur beton bertulang dengan panjang bentang tidak lebih dari 100 meter, [14]. Untuk jembatan berbentang panjang (> $100 \mathrm{~m}$ ), atau yang menggunakan sistem struktur khusus, atau material khusus, atau cara pelaksanaan yang khusus, perlu diperhatikan kondisi-kondisi khusus yang sesuai, di mana usulan dan analisis struktur yang telah memperhitungkan kondisikondisi khusus tersebut harus dilakukan secara rinci, dan diserahkan kepada yang berwenang beserta semua pembuktian kebenarannya. Beton normal yang dimaksud dalam standar ini adalah beton yang dibuat dengan menggunakan semen portland, mempunyai massa jenis sekitar 2400 $\mathrm{kg} / \mathrm{m}^{\wedge} 3$, dan mempunyai kuat tekan (berdasarkan benda uji silinder) antara $20 \mathrm{MPa}$ sampai dengan $60 \mathrm{MPa}$ (setara dengan K250 - K700 berdasarkan benda uji kubus), termasuk beton ringan yang mempunyai massa jenis tidak kurang dari $2000 \mathrm{~kg} / \mathrm{m}^{\wedge} 3$ dan mempunyai kuat tekan antara 20 MPa sampai dengan 40 Mpa [15]. Walaupun demikian, standar ini bisa berlaku untuk penggunaan beton bermutu tinggi dengan kuat tekan yang lebih tinggi dari $60 \mathrm{MPa}$, atau beton ringan dengan massa jenis yang kurang dari $2000 \mathrm{~kg} / \mathrm{m}^{\wedge} 3$, asalkan bila dianggap perlu bisa dilakukan penyesuaian pada perilaku material beton tersebut, berdasarkan suatu acuan teknis atau hasil penelitian yang bisa diterima oleh yang berwenang, [16].

a.) Menentukan tebal plat

Bedasarkan SK SNI T-15-1991 pasal 3.2.5 bahwa tebal plat minimum diambil rumus :

h_min $=\operatorname{In} / 28(0,4+$ fy/700 $)$

Dimana :

In $\quad=$ Panjang bersih bentang yang terpanjang

fy $\quad=$ Tegangan leleh baja

b.) Penulangan beton

Beton bertulang direncanakan runtuh secara perlahan dan bertahap, hal ini dimungkinkan apabila tulangan tarik beton terlebih dahulu meleleh sebelum renggangan beton mencapai maksimum ( under reinforced ), [18][19].

Dengan dasar perencanaan tersebut, jumlah tulangan yang digunakan pada penampang beton dibatasi menurud SKSNI-1991 pasal 3.3.3. Anggapan pembatasan jumlah tulangan tersebut 
berkaitan dengan rasio penulangan ( $\rho$ ) yaitu perbandingan antara luas penampang tulangan baja tarik ( As ) dengan luas efektif penampang. Dapat dirumuskan sebagai berikut :

$\rho \quad=\mathrm{As} /(\mathrm{b} \times \mathrm{d})$

Pembatasan tulangan yang dimaksud dalam SKSNI T-15-1991-03 pasal 3.3.3 adalah rasio penulangan maksimum yang diijinkan, dibatasi sebesar 0,75 dari rasio penulangan dalam keadaan seimbang $(\rho b)$.

$\rho \_\max \quad=0,75 . \rho b$

Besarnya rasio penulangan dalam keadaan seimbang menurud SKSNI T-15-1991-03 pasal 3.3.3 adalah :

$\rho b \quad=\left(0,85 \times f^{\prime} c\right) /$ fy $\times \beta \times 600 /(600+f y)$

Sedangkan untuk rasio penulangan minimum menurud SKSNI T-15-1991-03 pasal 3.3.5.1 adalah :

$\rho \_\min \quad=1,4 / \mathrm{fy}$

Syarat rasio penulangan dalam beton bertulang harus memenuhi ketentuan sebagai berikut : $\rho \_\min <\rho<\rho \_\max$

Struktur harus direncanaakan hingga semua penampang harus mempunyai kuat rencana minimum sama dengan kuat perlu yang dihitung berdasarkan kombinasi beban gaya terfaktor. Persamaan tersebut disederhanakan menjadi :

$\mathrm{M} \_\mathrm{u} \quad=\varphi \mathrm{M} \_\mathrm{n}$

Untuk mencari rasio penulangan ( $\rho$ ) yang akan menentukan luas tulangan dari penampang beton, dapat digunakan rumus sebagai berikut :

$\rho=\left(0,85 . f^{\prime} \mathrm{c}\right) / \mathrm{fy}\left[1-\sqrt{ }\left(1-(2 \cdot R n) /\left(0,85 . f^{\prime} \mathrm{c}\right)\right)\right]$

Dimana :

$\mathrm{Rn} \quad=\mathrm{M} \_\mathrm{u} /\left(\mathrm{b} . \mathrm{d}^{\wedge} \mathrm{2}\right)$

Dengan $\mathrm{M} \_\mathrm{u}=$ momen ultimate/momen terfaktor penampang

Jika $\rho$ yang diperoleh lebih kecil dari $\rho \_$min, maka yang diambil adalah $\rho \_$min, sehingga luas tulangan dapat dicari dengan rumus :

As $\quad=\rho . b . d$

Jarak tulangan perlu dihitung dengan menggunakan rumus :

S

$=\left(1 / 4 \times \llbracket \varnothing \_t u l \rrbracket \wedge 2 \times\right.$ b $) / A s$. ...[20] 


\section{HASIL DAN PEMBAHASAN}

\subsection{Perhitungan Beban}

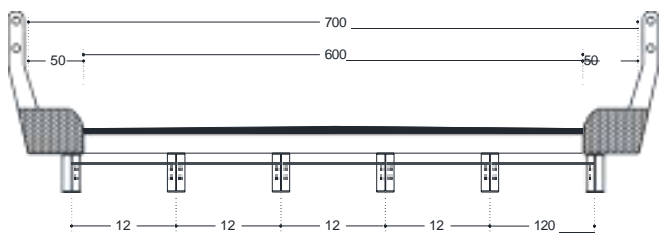

Gambar 2. Potongan Melebar Jembatan

Tabel 1. Data Teknik Jembatan

\begin{tabular}{|c|c|c|c|c|}
\hline KETERANGAN & SIMBOL & NILAI & \multicolumn{2}{|l|}{ SATUAN } \\
\hline Tebal slap lantai jembatan & & 0,2 & \multicolumn{2}{|l|}{$\mathrm{m}$} \\
\hline Tebal lapisan aspal & & 0,1 & \multicolumn{2}{|l|}{$\mathrm{m}$} \\
\hline Tebal genangan air hujan & & 0,05 & \multicolumn{2}{|l|}{$\mathrm{m}$} \\
\hline Jarak antara girder baja & & 1,2 & \multicolumn{2}{|l|}{$\mathrm{m}$} \\
\hline Lebar Jalur Lalu-lintas & & 6 & \multicolumn{2}{|l|}{$\mathrm{m}$} \\
\hline Lebar trotoar & & 0,5 & \multicolumn{2}{|l|}{$\mathrm{m}$} \\
\hline Lebar total Jembatan & & 7 & \multicolumn{2}{|l|}{$\mathrm{m}$} \\
\hline Panjang bentang jembatan & & 12 & \multicolumn{2}{|l|}{$\mathrm{m}$} \\
\hline Mutubaja & $\mathrm{Bj}$ & \multicolumn{3}{|c|}{24} \\
\hline Tegangan leleh baja & fy & 24 & \multicolumn{2}{|l|}{ Mpa } \\
\hline Tegangan dasar & $\mathrm{Fs}=\mathrm{Fy} / 1.5$ & 16 & \multicolumn{2}{|l|}{ Mpa } \\
\hline Modulus elastis baja, & Es & 210000 & \multicolumn{2}{|l|}{ Mpa } \\
\hline $\begin{array}{l}\text { Ntuk baja tulangan dengan } \\
\emptyset>12 \mathrm{~m}\end{array}$ & $\mathrm{~m} \quad \mathrm{U}$ & \multicolumn{3}{|c|}{39} \\
\hline Tegangan leleh baja, & $\mathrm{Fy}=\mathrm{U} * 10$ & 390 & \multicolumn{2}{|l|}{ Mpa } \\
\hline $\begin{array}{l}\text { Ntuk baja tulangan dengan } \\
\emptyset>12 \mathrm{~m} \\
\end{array}$ & $\mathrm{~m} \quad \mathrm{U}$ & \multicolumn{3}{|c|}{24} \\
\hline Tegangan leleh baja, & $\mathrm{Fy}=\mathrm{U}^{*} 10$ & 240 & \multicolumn{2}{|l|}{ Mpa } \\
\hline MutuBeton & $\mathrm{K}$ & \multicolumn{3}{|c|}{300} \\
\hline Kuat tekan beton, & $\mathrm{fc}^{\prime}$ & 24,9 & \multicolumn{2}{|l|}{ Mpa } \\
\hline Modulus elastis beton & $\mathrm{Ec}=4700 \sqrt{\mathrm{fc}^{\prime}}$ & 23453 & \multicolumn{2}{|l|}{ Mpa } \\
\hline Angka Poisson & \multicolumn{3}{|c|}{$u$} & 0,2 \\
\hline Modulus Geser & $\mathrm{G}=\mathrm{Ec} /\left[2^{*}(1+\mathrm{U})\right]$ & 9772,1 & Mpa & \\
\hline Koefisien Muai Panjang untuk & $\alpha$ & 1,E-05 & Mpa & \\
\hline \multicolumn{5}{|l|}{ SpesificGrafity } \\
\hline Berat baja & ws & 77,0 & $\mathrm{kN} / \mathrm{m}^{3}$ & \\
\hline Berat beton bertulang & $\mathrm{wc}$ & 25,0 & $\mathrm{kN} / \mathrm{m}^{3}$ & \\
\hline Berat beton tidak bertulang & w'c & 24,0 & $\mathrm{kN} / \mathrm{m}^{3}$ & \\
\hline Berat Lapisan Aspal & wa & 22,0 & $\mathrm{kN} / \mathrm{m}^{3}$ & \\
\hline
\end{tabular}

Sumber : Analisa Pengamatan

a.) Beban Mati

Beban mati pada plat lantai jembatan ditinjau selebar $1 \mathrm{~m}$ 
Berat jenis beton $\quad=2,5 \mathrm{t} / \mathrm{m}^{\wedge} 3$

Tebal plat lantai $\quad=0,2 \mathrm{~m}$

Berat sendiri plat ( Q_MS ) $=1 \times 0,2 \times 2,5=0,5 \mathrm{t} / \mathrm{m}=5 \mathrm{kN} / \mathrm{m}$

b.) Beban Mati Tambahan

Untuk lebih mudahnya perhitungan dapat dilihat pada tabel di bawah

Tabel 2. Perhitungan beban mati tambahan

\begin{tabular}{|c|c|c|c|c|}
\hline NO & JENIS & TEBAL $(\mathbf{m})$ & BERAT JENIS $\left(\mathbf{k N} / \mathbf{m}^{\mathbf{3}}\right)$ & BEBAN $(\mathbf{k N} / \mathbf{m})$ \\
\hline 1 & Lapisan aspal & 0,10 & 22 & 2,2 \\
\hline 2 & Air hujan & 0,05 & 10 & 0,5 \\
\hline \multicolumn{5}{r|}{ BEBAN MATI TAMBAHAN $\left(Q_{\mathrm{MA}}\right)$} \\
\hline
\end{tabular}

Sumber : Analisa Pengamatan

Tabel 3. Perhitungan tegangan yang timbul

\begin{tabular}{|c|c|c|c|c|c|}
\hline \multicolumn{3}{|c|}{ Tegangan yang terjadi pada sisi } & Atas beton & Atas baja & Bawah baja \\
\hline No & Jenis beban & Momen & Ftc (Mpa) & fts (Mpa) & fbs (Mpa) \\
\hline 1 & Berat sendiri & 101,12 & 1,391 & 4,357 & 24,854 \\
\hline 2 & Beban mati tambahan & 59,05 & 0,563 & 1,762 & 10,050 \\
\hline 3 & Beban lajur "D" & 304,73 & 1,925 & 6,028 & 34,384 \\
\hline 4 & Gaya rem & 45,93 & 0,304 & 0,951 & 5,424 \\
\hline 5 & Beban angin & 14,70 & 0,140 & 0,438 & 2,500 \\
\hline 6 & Beban gempa & 16,039 & 0,197 & 0,618 & 3,523 \\
\hline
\end{tabular}

Sumber : Analisa Pengamatan

c.) Beban Truk " $\mathrm{T}$ "

Beban hidup pada lantai jembatan berupa beban roda ganda oleh Truk (beban T) yang besarnya $\mathrm{T}=100 \mathrm{kN}$. Factor beban dinamis untuk pembebanan truk diambil DLA $=0,3$, maka :

Beban truck $P_{T T}=(1+\mathrm{DLA}) \mathrm{x} \mathrm{T}$

$$
=(1+0,3) \times 100=130 \mathrm{kN}
$$

d.) Beban Angin

Beban garis merata tambahan arah horisontal pada permukaan lantai jembatan akibat angin yang meniup kendaraan di atas jembatan dihitung dengan rumus :

$T_{E W} \quad=0,0012 W\left(V_{W}\right)^{2}$

Dengan : $C_{W}=$ koefisien seret $=1,2$

$V_{W} \quad=$ kecepatan angin rencana $=35 \mathrm{~m} / \mathrm{det}$

$T_{E W} \quad=0,0012 \times 1,2 \times(35)^{2}=1,764 \mathrm{kN} / \mathrm{m}$ 


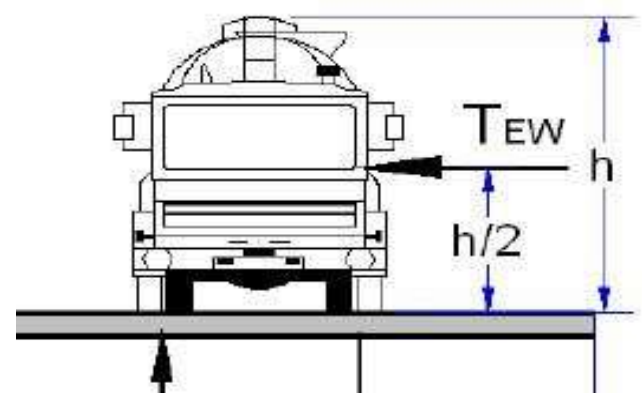

Gambar 3. Kendaraan yang terkena beban angin

Bidang vertikal yang ditiup angin merupakan bidang samping kendaraan dengan tinggi $2,00 \mathrm{~m}$ di atas lantai jembatan $(\mathrm{h}=2,00 \mathrm{~m})$. Nilai transfer beban angin ke lantai kendaraan :

$P_{E W}=\frac{\frac{1}{2} \times h}{X \times T_{E W}} \ldots \ldots \ldots \ldots \mathrm{X}=$ jarak antar roda kendaraan $=1,75 \mathrm{~m}$

$=\frac{\frac{1}{2} \times 2}{1,75 \times 1,764}=1,008 \mathrm{kN}$

\subsection{Section Properties Sebelum Komposit}

Bentang jembatan antar pilar $=12 \mathrm{~m}$.

a.) Penampang

$\frac{L s}{d}>\frac{1,25 \times b}{t f}$

$\frac{10800}{400}>\frac{1,25 \times 200}{13}$

$27>19,230$....... (OK)

$\frac{d}{t w}<75$

$\frac{400}{8}<75$

$50<75$ ..$(\mathrm{OK})$

b.) Lendutan pada baja sebelum komposit

Qt $\quad=11,09 \mathrm{kN} / \mathrm{m}$

Ls $\quad=10,80 \mathrm{~m}$

Es $\quad=210000$

$\mathrm{Mpa} \quad=210000000 \mathrm{kpa}$

Ix $\quad=2,37 \cdot 10^{5} \mathrm{~mm}^{4}=0,00237 \mathrm{~m}^{2}$

d $=\frac{\frac{5}{384} \times Q t \times L s^{4}}{E s \times I X}$

$=\frac{\frac{5}{384} \times 11,09 \times 10,80}{210000000 \times 0,00237}$

Syarat lendutan $\quad$ d $\quad<$ Ls/240

$0,0313<10,8 / 240$

$0,0313<0,045$ ( OK ) 
c.) Beban lajur "D"

Beban kendaraan yang berupa beban lajur " D " terdiri atas beban terbagi rata ( Uniformly Distributed Load ), UDL dan beban garis ( Knife Edge Load ), KEL. UDL mempunyai intensitas q ( Kpa ) yang besarnya tergantung pada panjang total yang dibebani lalu lintas atau dinyatakan dengan rumus :

$\mathrm{q}=8 \mathrm{kpa}$ untuk bentang $\leq 30 \mathrm{~m}$

$\mathrm{q}=8 \times(15$

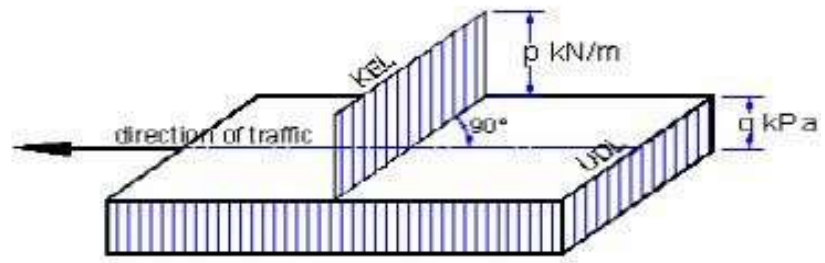

Gambar 4. Beban " D "

mempunyai intensitas sebesar $\mathrm{P}=44 \mathrm{kN} / \mathrm{m}$

Faktor beban dinamis ( Dinamic Load Allowance ) untuk KEL diambil sebagai berikut :

DLA $=0,4$ untuk $\mathrm{L} \leq 50$

DLA $=0,4-0,0025 *(\mathrm{~L}-50)$ untuk $50<\mathrm{L}<90$

DLA $=0,3$

Untuk L > 90

Beban lajur " D " $=\mathrm{QTD}=\mathrm{q}$ x $\mathrm{S}=8 \times 1,2=9,6 \mathrm{kN} / \mathrm{m}$

Beban garis $(\mathrm{PTD})=(1+$ DLA $) \times \mathrm{p} \mathrm{x} \mathrm{S}=(1+0,4) \times 44 \times 1,2=54,92 \mathrm{kN}$

$M_{\max }=\frac{1}{8} \mathrm{x} \mathrm{QTD} \times \mathrm{Ls}^{2}+1 / 4 \times \mathrm{PTD} \times \mathrm{L}$

$V_{\max }=1 / 2 \times \mathrm{QTD} \times \mathrm{Ls}+1 / 2 \times \mathrm{PTD}$

$=\frac{1}{8} \times 9,6 \times 10,8^{2}+1 / 4 \times 54,92 \times 12$

$=1 / 2 \times 9,6 \times 10,8+1 / 2 \times 54,92$

$=304,73 \mathrm{kNm}$

$=79,30 \mathrm{kN}$

d.) Gaya Rem

Besarna gaya rem tergantung pada panjang total jembatan ( L ) sebagai berikut :

Gaya rem, TTB $=250 \mathrm{kN}$ untuk $\mathrm{L}<80 \mathrm{~m}$

Gaya rem, TTB $=250+2,5(\mathrm{~L}-80) \mathrm{kN}$ untuk $80<\mathrm{L}<180 \mathrm{~m}$

Gaya rem, TTB $=500 \mathrm{kN}$ untuk $\mathrm{L}>180 \mathrm{~m}$

Besarnya gaya rem $($ TTB $)=\frac{250}{n}=\frac{250}{5}=50 \mathrm{kN}$

Jarak lengan terhadap pusat tampang grider (y) 


$$
\begin{aligned}
& \mathrm{y}=1,8+0.1+0,304 \\
& =2,204 \\
& M_{\max }=1 / 2 \times \text { TTB } \times \mathrm{y} \\
& V_{\max }=\frac{T T B \times y}{L} \\
& =1 / 2 \times 50 \times 2,204 \\
& =\frac{45,93 \times 2,204}{85,2}
\end{aligned}
$$

e.) Beban Angin

Beban garis merata tambahan arah horizontal pada permukaan lantai jembatan akibat angin yang meniup kendaraan di atas jembatan dapat dihitung dengan menggunakan rumus :

$\mathrm{TEW}=0,0012 \times \mathrm{CW} \times\left(V_{w}\right)^{2}$

Dimana,

$\mathrm{Cw}=$ koefisien seret $=1,2$

$\mathrm{Vw}=$ Kecepatan angin rencana $=35 \mathrm{~m} / \mathrm{det}$

$\mathrm{TEW}=0,0012 \times 1,2 \times 35^{2}=1,764 \mathrm{kN}$

Bidang yang terkena gaya angin merupakan bidang samping kendaraan dengan tinggi $2 \mathrm{~m}$ dengan lebar antar as roda $(\mathrm{x})=1,75 \mathrm{~m}$.

Transfer beban angin kelantai kendaraan $(\mathrm{QEW})=\frac{\frac{1}{2} \times h}{x} \mathrm{x}$ TEW

$=\frac{\frac{1}{2} \times 2}{1,75} \times 1,764=1,008 \mathrm{kN} / \mathrm{m}$

Momen dan gaya geser maksimum pada girder akibat beban angin :

$M_{\max }=\frac{1}{8} \times \mathrm{QEW} \times \mathrm{Ls}^{2}$

$V_{\max }=1 / 2 \times \mathrm{QEW} \times \mathrm{Ls}$

$=\frac{1}{8} \times 1,008 \times 10,8^{2}$

$=1 / 2 \times 1,008 \times 10,8=14,70 \mathrm{kNm}=5,44 \mathrm{kN}$

f.) Beban Gempa

Gaya gempa vertical pada balok dihitung dengan menggunakan percepatan vertical kebawah sebesar $0,1 \times \mathrm{g}$, denga $\mathrm{g}=$ percepatan gravitasi

Gaya gempa vertical rencana $(\mathrm{QEQ})=0,1 \mathrm{x} \mathrm{Wt}$

$\mathrm{Wt}=$ Beban Struktur $(\mathrm{Qms}+\mathrm{Qma})$

$\mathrm{QEQ}=0,1 \times(6,94+4,05)=1,1 \mathrm{kN} / \mathrm{m}$

$M_{\max }=\frac{1}{8} \mathrm{x} \mathrm{QEQ} \times \mathrm{Ls}^{2}$

$V_{\max }=1 / 2 \times$ QEQ $\times$ Ls

$=\frac{1}{8} \times 1,1 \times 10,8^{2}=1 / 2 \times 1,1 \times 10,8=16,039 \mathrm{kNm}=5,94 \mathrm{kN}$ 


\subsection{Kontrol Tegangan Pada Girder Komposit}

Dari perhitungan sebelumnya diperoleh :

- Wtc $=12873890,7 \mathrm{~mm}^{3}$

- Wts $=88662844,8 \mathrm{~mm}^{3}$

- $\mathrm{Wbs}=8229291,3 \mathrm{~mm}^{3}$

- $\mathrm{N}=9,13$

Tegangan pada girder komposit :

Tegangan pada sisi atas beton $(\mathrm{ftc})=\frac{M \times 10^{6}}{n \times W t c}$

Tegangan pada sisi atas baja ( fts $)=\frac{M \times 10^{6}}{W t s}$

Tegangan pada sisi bawah baja $($ fbs $)=\frac{M \times 10^{6}}{W b s}$

Hasil perhitungan tegangan pada gilder komposit di sajikan dalam tabel berikut :

Tabel 4. Perhitungan tegangan yang timbul

\begin{tabular}{|c|c|c|c|c|c|}
\hline \multicolumn{3}{|c|}{ Tegangan yang terjadi pada sisi } & Atas beton & Atas baja & Bawah baja \\
\hline No & Jenis beban & Momen & Ftc (Mpa) & fts (Mpa) & fbs (Mpa) \\
\hline 1 & Berat sendiri & 101,12 & 1,391 & 4,357 & 24,854 \\
\hline 2 & Beban mati tambahan & 59,05 & 0,563 & 1,762 & 10,050 \\
\hline 3 & Beban lajur "D" & 304,73 & 1,925 & 6,028 & 34,384 \\
\hline 4 & Gaya rem & 45,93 & 0,304 & 0,951 & 5,424 \\
\hline 5 & Beban angin & 14,70 & 0,140 & 0,438 & 2,500 \\
\hline 6 & Beban gempa & 16,039 & 0,197 & 0,618 & 3,523 \\
\hline
\end{tabular}

Sumber : Analisa Pengamatan

Tabel 5. kombinasi-kombinasi:

\begin{tabular}{|c|c|c|c|c|}
\hline \multicolumn{2}{|c|}{ Tegangan yang terjadi pada sisi } & Atas beton & Atas baja & Bawah baja \\
\hline No & Jenis beban & Ftc (Mpa) & fts (Mpa) & fbs (Mpa) \\
\hline 1 & Berat sendiri & 1,391 & 4,357 & 24,854 \\
\hline 2 & Beban mati tambahan & 0,563 & 1,762 & 10,050 \\
\hline 3 & Beban lajur "D" & 1,925 & 6,028 & 34,384 \\
\hline 4 & Gaya rem & 0,304 & 0,951 & 5,424 \\
\hline 5 & Beban angin & 0,140 & 0,438 & 2,500 \\
\hline 6 & Beban gempa & 0,197 & 0,618 & 3,523 \\
\hline \multicolumn{2}{r|}{} & 4,520 & 14,155 & 80,734 \\
\hline & Jumlah & OK & OK & OK \\
\hline
\end{tabular}

Sumber : Analisa Pengamatan

\section{KESIMPULAN}

Dalam penyusunan Tugas Akhir ini, banyak permasalahan yang timbul dalam pelaksanaan pekerjaan Jembatan Sendang (Ruas Jalan Tugu - Pabyongan). 
Dari hasil kajian dapat diambil kesimpulan bahwa Jembatan Sendang ( Ruas Jalan Tugu - Pabyongan ) dengan bentang 36 meter ( 12 meter +12 meter +12 meter ) dengan lebar 6 meter, yaitu :

1. Gaya yang terbesar yang bekerja pada jembatan meliputi : momen ultimite tumpuan sebesar $=34,7 \mathrm{kNm}$ dan momen lapangan ultimit sebesar $=23,8 \mathrm{kN}$, beban mati $=101,12 \mathrm{kNm}$ ,beban hidup $=11,09 \mathrm{kN} / \mathrm{m}$, beban ' $\mathrm{D}$ ' $=304,73 \mathrm{kNm}$, beban ' $\mathrm{T}$ ' $=130 \mathrm{kN}$, beban rem $=$ $45,93 \mathrm{kNm}$, beban angin $=14,70 \mathrm{kNm}$, beban gempa $=1,1 \mathrm{kN} / \mathrm{m}$

2. Dari pembebanan yang ada ditentukan Plat jembatan setebal 0,2 $\mathrm{m}$ dengan tulangan pokok $\varphi 14-100$ dan memakai tulangan sengkang $\varphi 10-200$.

3. Kontrol - kontrol yang di gunakan syarat lendutan $\mathrm{d}<\mathrm{Ls} / 240 \quad 0,0313<10,8 / 240 \rightarrow \mathrm{OK}$, kontrol tegangan kip $\mathrm{f}=16,77 \mathrm{Mpa}$

4. Profil gelagar digunakan WF 400.200.8.13, dengan perhitungan beban struktur dan gaya yang bekerja pada jembatan, penggunaan profil gelagar tersebut aman menerima tegangan dan lendutan akibat gaya-gaya pada struktur atas.

Untuk mencapai perencanaan yang baik dan benar-benar matang maka diperlukan studi kelayakan yang teliti dan referensi yang lengkap.

\section{SARAN}

Dalam pelaksanaan dengan memeperhatikan dan mengamati jenis pekerjaan jembatan dan untuk mendapatkan hasil yang maksimal, maka diperlukan :

1) Mengadakan Perhitungan yang matang untuk menciptakan suatu struktur jembatan yang berdaya guna

2) Perlu diadakan survey lokasi yang mendetail dalam perencanaan struktur jembatan

3) Mengadakan estimasi tentang kemungkinan-kemungkinan yang akan terjadi di masa yang akan datang sehingga konstruksi hasil perencanaan tersebut dapat memenuhi standart untuk masa kini dan masa yang akan datang.

4) Pekerjaan diperlukan tenaga-tenaga ahli yang benar-benar berpengalaman sehingga kualitas konstruksi dapat sesuai dengan hasil perencanaan.

5) Untuk menghindari kerusakan kerusakan jembatan dengan metode komposit baja dan beton yaitu dengan memperbesar faktor keamanan serta mempertahankan segi perawatan yang lebih hemat, mudah dan ekonomis serta mampu memenuhi harapan dalam pelaksanaan bagi kita semua.

\section{UCAPAN TERIMAKASIH}

Dalam penyusunan artikel ini, penulis ucapkan terimakasih kepada dosen pembimbing dan Universitas Kadiri. Penulis berharap agar artikel ini dapat bermanfaat bagi pembaca. 


\section{DAFTAR PUSTAKA}

[1] H. J. Struyk and K. H. C. W. Van Der Veen, "Jembatan,” PT. Pradnya Paramita, 1984.

[2] A. Sunanda, J. T. Sipil, and F. Teknik, "Kajian stabilitas pondasi kelompok tiang pancang rencana jembatan mualaf kecamatan tenggarong," KURVA $S J$. Mhs., vol. 4, no. 2, pp. 519-524, 2016.

[3] Badan Standardisasi Nasional, "RSNI T-02-2005 Pembebanan untuk Jembatan.” 2005.

[4] Hadi Y. CE, "Perhitungan Konstruksi Baja,” Yustadi Offset, 2000.

[5] ULP Dinas Pekerjaan Umum dan Perumahan Rakyat Kabupaten Tulungagung, "Dokumen Lelang Jembatan Sendang (Ruas Jalan Tugu - Pabyongan),” 2016.

[6] A. I. Candra, S. Anam, Z. B. Mahardana, and A. D. Cahyono, "Studi Kasus Stabilitas Struktur Tanah Lempung Pada Jalan Totok Kerot Kediri Menggunakan Limbah Kertas," UkaRsT, vol. 2, no. 2, pp. 88-97, 2018.

[7] R. M. Simatupang, L. Susanti, and E. A. Perkasa, "Studi Analisis dan Eksperimental Pengaruh Perkuatan Sambungan Pada Struktur Jembatan Rangka Canai Dingin Terhadap Lendutannya," Rekayasa Sipil, vol. 10, no. 3, pp. 205-210, 2016, doi: 10.21776/ub.rekayasasipil.2016.010.02.05.

[8] Departemen Permukiman dan Prasarana Wilayah, "Pd T-04-2004-B Perencanaan Beban Gempa Untuk Jembatan.” 2004.

[9] E. Sari, "Analisis Resiko Proyek Pada Pekerjaan Jembatan Sidamukti - Kadu Di Majalengka Dengan Metode Fmea Dan Decision Tree," J-Ensitec, vol. 2, no. 02, pp. 3846, 2016, doi: 10.31949/j-ensitec.v2i02.306.

[10] Badan Standardisasi Nasional, "SNI 07-2052-2002 Baja tulangan beton,” 2002.

[11] R. Gunawan, "Tabel Profil Konstruksi Baja,” Yogyakarta : Kanisius, 1988.

[12] Direktorat Jendral Marga Bina, "Standard spesifikasi untuk jembatan jalan raya type balok gabungan," Jakarta Badan Penerbit Pekerj. Umum, 1976.

[13] Badan Standardisasi Nasional, "Standar perencanaan ketahanan gempa untuk jembatan," SNI, 2008.

[14] Badan Standarisasi Nasional, "SNI 1725:2016 Pembebanan untuk Jembatan,” 2016.

[15] J. Ikhsan and W. Hidayat, "Pengaruh bentuk pilar jembatan terhadap potensi gerusan lokal," J. Ilm. Semesta Tek., vol. 9, no. 2, pp. 124-132, 2006. 
[16] Badan Standardisasi Nasional, "RSNI T-12-2004 Perencanaan Struktur Beton untuk Jembatan.” 2004.

[17] Departmen Pekerjaan Umum, "SKSNI T-15-1991 Tata Cara Perhitungan Struktur Beton untuk Bangunan Gedung," 1991.

[18] Badan Standardisasi Nasional, "SNI 03 - 2847 - 2002 SNI Tata Cara Perhitungan Struktur Beton Untuk Bangunan Gedung," 2002.

[19] J. Onding, L. S. Balamba, O. B. A. Sompie, and A. N. Sarajar, "Analisis Kestabilan Pondasi Jembatan Studi Kasus : Jembatan Essang-Lalue,” J. Sipil Statik, vol. 1, no. 11, pp. 730-744, 2013.

[20] Departmen Pekerjaan Umum, "RSNI T-03-2005 Perencanaan struktur baja untuk jembatan," 2005. 